\title{
Therapy of posttransplant poor graft function with eltrombopag
}

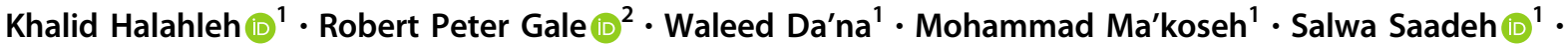 \\ Waseem Alan ${ }^{1} \cdot$ Dana Yousef $^{4} \cdot$ Rozan AL-Far $^{1} \cdot$ Isra Muradi $^{3} \cdot$ Husam Abujazar ${ }^{1} \cdot$ Hasan Hashem ${ }^{5}$
}

Received: 9 April 2020 / Revised: 28 May 2020 / Accepted: 9 June 2020 / Published online: 22 June 2020

(c) Springer Nature Limited 2020

Poor graft function is a serious complication of allogeneic hematopoietic cell transplantation. The diagnosis is based on presence of $\geq 2$ of the following: (1) haemoglobin concentration $<100 \mathrm{~g} / \mathrm{L}$; (2) neutrophils $<1.0 \times 10 \mathrm{E}+9 / \mathrm{L}$; and (3) platelets $<30 \times 10 \mathrm{E}+9 / \mathrm{L}$ ) on day $\geq 30$ post transplant [1]. Other criteria include receiving $\mathrm{RBC}$ and platelet requiring transfusions, decreased bone marrow cellularity, complete donor chimerism and no graft-versus-host disease (GvHD) or relapse. Late failure of platelet recovery is defined as a decrease of platelet to $<20 \times 10 \mathrm{E}+9 / \mathrm{L}$ for 7 consecutive days or receiving platelet transfusions after achieving sustained platelets $\geq 50 \times 10 \mathrm{E}+9 / \mathrm{L}$ without platelet transfusions for 7 consecutive days post transplant. Poor graft function is reported in $5-25 \%$ of allotransplant recipients and is associated with increased morbidity and mortality [1]. Current therapies including RBC and platelet transfusions, intravenous immunoglobulin, molecularly cloned hematopoietic growth factors such as granulocyte- and granulocyte/macrophage colony-stimulating factors (G- and G/M-CSF), additional donor blood or bone marrow (termed a boost) or mesenchymal cells and/or a second transplant from the same or a different donor. These interventions are only partially effective [2,3]. Eltrombopag, an oral thrombopoietin receptor agonist, is reported effective in severe aplasia anaemia, idiopathic thrombocytopenic purpura and in thrombocytopenia from hepatitis-C infection [4-7]. There are six reports of

Khalid Halahleh

kh.06314@khcc.jo

1 Department of Medical Oncology, Adult Bone Marrow Transplantation, King Hussein Cancer Center, Amman, Jordan

2 Imperial College London, London, UK

3 University of Tripoli, Tripoli, Libya

4 Department of Nursing, Adult Bone Marrow Transplantation, King Hussein Cancer Center, Amman, Jordan

5 Department of Pediatrics, Pediatric Bone Marrow Transplantation, King Hussein Cancer Center, Amman, Jordan eltrombopag given to improve posttransplant graft function with encouraging results [8-12].

Between January 2013 and February 2019, 37 of 765 consecutive allotransplant recipients at our centre (5\%) developed poor graft function post transplant. Ten received a second transplant, all were aplastic anaemia and thalassaemia, and fourteen received eltrombopag. Seven of the fourteen eltrombopag recipients were male. Median age was 44 years (range, 8-61 years). Four previously received conventional pretransplant conditioning and ten received reduced-intensity conditioning. Eight donors were HLAidentical siblings and six were HLA-haplotype-matched relatives. Median CD34-positive cell dose was $5.38 \times 10 \mathrm{E}$ $+6 / \mathrm{kg}$ (range, $2.63-9.48 \times 10 \mathrm{E}+6 / \mathrm{kg}$ ). Median interval between transplant and diagnosis of poor graft function was 81 days (range, 24-300 days) and median interval to starting eltrombopag was 103 days (range, 24-300 days). Median weekly eltrombopag dose was $525 \mathrm{mg} /$ week (range, $350-700 \mathrm{mg} /$ week) and median treatment duration was 2.4 months (range, 0.4-12 months). Detailed data are displayed in the Table 1.

Six subjects had primary and eight had late poor graft function, six of whom had only thrombocytopenia. Eltrombopag was started at a dose of $50 \mathrm{mg} /$ day and increased by $25 \mathrm{mg}$ increments every 2 weeks if no response. Median haemoglobin concentration before eltrombopag was $86 \mathrm{~g} / \mathrm{L}$ (range, $60-140 \mathrm{~g} / \mathrm{L}$ ), median neutrophils $2.3 \times 10 \mathrm{E}+9 / \mathrm{L}$ (range, $2.0-8.5 \times 10 \mathrm{E}+9 / \mathrm{L}$ ) and platelets $21 \times 10 \mathrm{E}+9 / \mathrm{L}$ (range, $6-50 \times 10 \mathrm{E}+9 / \mathrm{L}$ ). Seven subjects had platelets $<20 \times 10 \mathrm{E}+9 / \mathrm{L}$ and eight had decreased or absent bone marrow megakaryocytes.

Eight subjects responded to eltrombopag with haemoglobin concentration $>100 \mathrm{~g} / \mathrm{L}$, neutrophils $>1.0 \times 10 \mathrm{E}$ +9 and platelets $>50 \times 10 \mathrm{E}+9 / \mathrm{L}$ without blood product transfusions or G- or G/M-CSF for $\geq 7$ consecutive days and with continued response after stopping the drug. Median interval to response was 30 days (range, 6-43 days). Median (range) platelets and WBC response dynamics are illustrated in Fig. 1. Median follow-up for responders was 


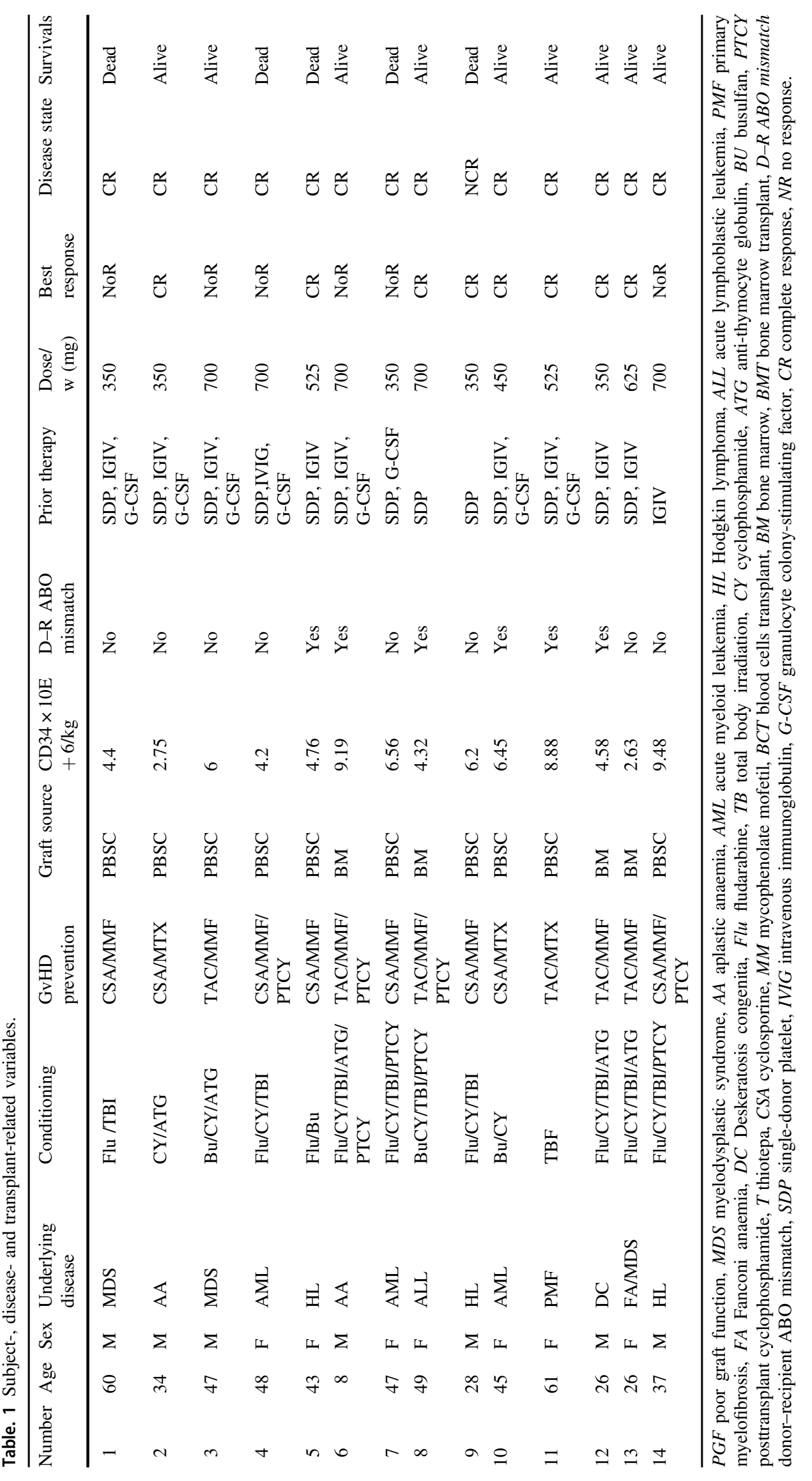



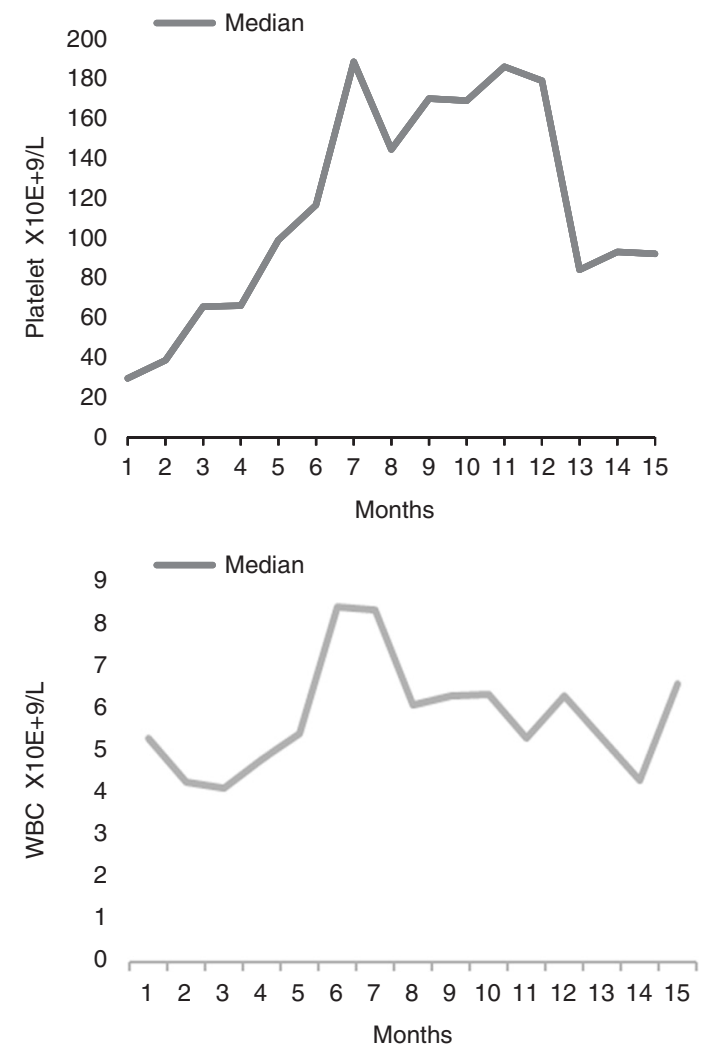

Fig. 1 Platelets and WBC response to eltrombopag. (a) Median (range) platelets (b) Median (range) WBC.

13 months (range, 6-43 months). The six subjects with adequate bone marrow responded. Only five of six subjects with late thrombocytopenia responded. The six of responders are alive at a median follow up of 14 months (range, 10-41 months) with normal blood cell concentrations. Two non-responders relapsed and died and two had ongoing infections and two had ongoing GvHD. There was no treatment-related morbidity or mortality including no cataracts or thrombosis.

In summary, 8 of 14 subjects with poor graft function failing prior therapies responded to eltrombopag. There were no major adverse events. All subjects with adequate bone marrow megakaryocytes responded. Eltrombopag is a safe and effective therapy of poor graft function post allotransplant.

Funding RPG acknowledges support from the National Institute of Health Research Biomedical Research Centre funding scheme.

\section{Compliance with ethical standards}

Conflict of interest The authors declare that they have no conflict of interest.
Publisher's note Springer Nature remains neutral with regard to jurisdictional claims in published maps and institutional affiliations.

\section{References}

1. Lee KH, Lee JH, Choi SJ, Lee JH, Kim S, Seol M, et al. Failure of trilineage blood cell reconstitution after initial neutrophil engraftment in patients undergoing allogeneic hematopoietic cell transplantation-frequency and outcomes. Bone Marrow Transplant. 2004;33:729-34.

2. Stasia A, Ghiso A, Galaverna F, Raiola AM, Gualandi F, Luchettie S, et al. CD34 selected cells for the treatment of poor graft function after allogeneic stem cell transplantation. Biol Blood Marrow Transplant. 2014;20:1440-3.

3. Liu $\mathrm{X}, \mathrm{Wu} \mathrm{M}$, Peng $\mathrm{Y}$, Chen $\mathrm{X}$, Sun J, Huang $\mathrm{F}$, et al. Improvement in poor graft function after allogeneic hematopoietic stem cell transplantation upon administration of mesenchymal stem cells from third-party donors: a pilot prospective study. Cell Transplant. 2014;23:1087-98.

4. Wong RSM, Saleh MN, Khelif A, Salama A, Portella MSO, Burgess P, et al. Safety and efficacy of long-term treatment of chronic/persistent ITP with eltrombopag: final results of the EXTEND study. Blood. 2017;130:2527-36.

5. Desmond R, Townsley DM, Dumitriu B, Olnes MJ, Scheinberg P, Bevans $\mathrm{M}$, et al. Eltrombopag restores trilineage hematopoiesis in refractory severe aplastic anemia that can be sustained on discontinuation of drug. Blood. 2014;123:1818-25.

6. Townsley DM, Scheinberg P, Winkler T, Desmond R, Dumitriu $\mathrm{B}$, Rios $\mathrm{O}$, et al. Eltrombopag added to standard immunosuppression for aplastic anemia. N Engl J Med. 2017;376: 1540-50.

7. McHutchison JG, Dusheiko G, Shiffman ML, Rodriguez-Torres M, Sigal S, Bourliere M, TPL102357 Study Group. et al. Eltrombopag for thrombocytopenia in patients with cirrhosisassociated hepatitis C. N Engl J Med. 2007;29:2227-36.

8. Pendra M, Seth J R, Rabi H. Use of thrombopoietin receptor agonists in prolonged thrombocytopenia after hematopoietic stem cell transplantation. Biol Blood Marrow Transplant. 2020; 26:65-73.

9. Marotta S, Marano L, Ricci P, Cacace F, Frieri C, Simeone L, et al. Eltrombopag for post-transplant cytopenias due to poor graft function. Bone Marrow Transplant. 2019;54:1346-53.

10. Popat UR, Ray G, Bassett RL Jr., Poon M-YC, Valdez BC, et al. Eltrombopag for post-transplant thrombocytopenia: results of phase II randomized double blind placebo controlled trial. Blood. 2015;12:738. (abstract 738).

11. Strickland SA, Wang XV, Cerny J, Rowe JM, Rybka W, Tallman MS, et al. A Novel PrECOG (PrE0901) Dose-Escalation Trial Using Eltrombopag: Enhanced Platelet Recovery During Consolidation Therapy in Acute Myeloid Leukemia. Leuk Lymphoma. 2020;1-9

12. Bento L, Bastida JM, García-Cadenas I, García-Torres E, Rivera D, Bosch-Vilaseca A, et al. Thrombopoietin receptor agonists for severe thrombocytopenia after allogeneic stem cell transplantation: Experience of the Spanish Group of Hematopoietic Stem Cell Transplant; Grupo Español de Trasplante Hematopoyético (GETH). Biol Blood Marrow Transplant. 2019; 25:1825-31. 